Article

\title{
Design of a Movement Therapy in the form of Taekwondo and its Effectiveness on Easement of Clinical Symptoms in Boys Suffering from Deficit Attention and Hyper Activity Disorder
}

\author{
Rahmatollah Azimi ${ }^{1,}{ }^{*}$, Morteza Tarkhan ${ }^{2}$, Seyed Reza Mirmehdy ${ }^{2}$ \\ ${ }^{1}$ Islamic Azad University, Tonekabon branch, Iran \\ 2 Department of Psychology, Payame Noor University, Tehran, Iran \\ * Correspondence: iran1107@yahoo.com
}

How to cite this paper: Azimi, R., Tarkhan, M.., \& Mirmehdy, S. R. (2021). The Design of a Movement Therapy in the form of Taekwondo and its Effectiveness on Easement of Clinical Symptoms in Boys Suffering from Deficit Attention and Hyper Activity Disorder [ADHD]: Effectiveness on Easement of Clinical Symptoms in boys suffering from Deficit Attention and Hyper Activity Disorder. Open Journal of Psychology, 1(1), 1-7. Retrieved from https://www.scipublications.com/journal/index.php/ojp/article/view/3

Received: April 19, 2021 Accepted: May 30, 2021 Published: May 31, 2021

Copyright: (c) 2021 by the authors. Submitted for possible open access publication under the terms and conditions of the Creative Commons Attribution (CC BY) license (http://creativecommons.org/licenses /by/4.0/).

\begin{abstract}
This research deals with Design of a Movement Therapy in the form of Taekwondo and its Effectiveness on Easement of Clinical Symptoms in boys suffering from Deficit Attention and Hyper Activity Disorder [ADHD]. In terms of objective, it is a practical research and in terms of how it gathered data it is a half-pilot research of pre \& post-test encompassing test and control groups. Samples were 32 children of 6-12 years of age who were ensured to have been suffering from ADHD as diagnosed by psychiatric clinics in Tehran. Sampling was made through easy method and test/control groups were formed randomly from among samples (each group containing16 members). ADHD was evaluated in samples using Conner's teaching questionnaire pre \& post-test questionnaire. To test group a 12-session long practice of movement therapy was prescribed in the form of Taekwondo. Findings were then analyzed using covariance analysis system. Results revealed that there is a meaningful relationship between movement therapy in the form of Taekwondo and easement of ADHD clinical symptoms in reliability of $\mathrm{P}<0.01$ ). Therefore, difference of averages can persuade us that movement therapy in the form of Taekwondo is effective on easement of clinical symptoms of ADHD.
\end{abstract}

Keywords: Attention deficit and hyperactivity disorder, Movement therapy, Conner test, Taekwondo

\section{Introduction}

Study on Attention Deficit and Hyperactivity started from the nineteenth century. The disorder was first posed by Henrich Hofman - a German practitioner- in 1845. In his story titled 'Restless Philip Story' he elaborated on this disorder. Philip is introduced as a very restless boy. Today Philip's characteristics are named as main symptoms of ADHD [1]. In the three speeches that George Stile delivered in London Health Academy in 1902, he drew attentions to ADHD. He tried to describe children who suffered from disorder that made them unable to internalize problems, tirelessness, neglect and hyperactivity as well as impulsiveness. He called the disorder as 'incomplete moral control' disorder: a disorder that causes problems in behavioral inhibitions of children [2]. ADHD is a disorder that encompasses neglect and hyperactivity. Each one of the two elements of this disorder are defined based on a series of behavioral criteria. Neglect asserts itself by carelessness and forgetfulness in normal routine activities as well as a number of other attentionrelated problems. Neglecting children are used to lose their things and are easily distracted. They are unable to follow an instruction or to organize their homework. Hyperactivity can be observed in child's restlessness, panic, irregular running, difficulties in being calm when playing and chattiness. A child can be diagnosed to be suffering from ADHD when s/he shows neglect and hyperactivity or both. It is not surprising that such children face serious educational problems in school. If they show hyperactivity behavior 
they are almost rejected by their peers and face accidents and are injured most of the time [3]. Studies in international scale demonstrate that ADHD rate is 3 to 7 percent among children and adolescents. This rate differs from country to country depending on how sampling is being done and what sort of instrument is used for that [4]. The rate has been considered for Iran's cities which was found to be ranging from 3 to 12 percent [5]. ADHD is an irregular state which can be recognized by continual activities which are characterized by lack of goal and constant changing. Its signs include starting prior to seven years of age, lasting for more than six months without symptoms of mental, emotional and physical disorders in behavior [6]. This disorder also shows itself either at home or at school making child face many social and educational dilemmas. It has been estimated that rate of this disorder in boys is three times more than girls. It lasts until adolescence in 50 to 80 percent of cases and until adulthood in 30 to 50 percent [7]. It is important to focus on how to treat the disorder because it poses a high risk in terms of inclination to delinquency, drugs, mistreatments and oppositional defiant disorder. Research indicates that 35 percent of ADHD children declare oppositional defiant disorder and 25percent mistreatment disorder making their families distressed [8]. Some interventions are thought to be better than others in treating such disorders: medication intervention, behavioral therapy, behavioral-cognitive therapy, combinational and complementary intervention [9].The most common medication intervention for ADHD children is prescribing central nervous system stimulants which despite having some constructive effects they bring about side effects as well including decreased appetite, lost weight, headache and damage to brain's nervous tissue [8]. Behavioral therapy is referred to a certain set of methods and techniques extracted from psychological experimental findings - particularly in learning psychology- with an intention to help individual overcome dilemmas. Although it may seem that behavioral psychology is theoretical source (reference) of this therapy, this therapeutic approach is not limited to behavioral psychology and some other experimental psychological findings are involved in devising [9]. Another therapeutic approach is behavioral-cognitive one which helps individual to change deviated models of his/her inefficient behaviors. In some points of treatment, behavior is focused while in some points cognition becomes center of focus [10]. Developmental psychologists maintain that play and movement are two major elements for development of language, problem-solving skill, innovativeness, cognitive-movement abilities in humans. Ferasat (1992) believes that a child with poor movement skills will, due to being rejected in plays, face developmental and behavioral disorders seriously. So, movement constitutes the backbone of growth and development in child triggering them towards evolution. Put it another way, movement is the first means of communication and discovery of the world around [10]. That is why it can be described as a means of evolution in humans as well. Study of movement in children has a long history. Philosophers and educators have always linked movement with learning capability. Plato includes gymnastic movements in the first stage of his education in his utopia. Aristotle believes human soul is locked by two elements: 'sense' and 'mind plus movement'. Spinoza says 'develop your body in order to be able to do many works. It helps you develop your mind and attain rational mind.' Movement is known by physiologists and neurologists as a way to stimulate neural paths of brain which contributes to organizing brain. Habb- a neurologist- describes initial movements as integral part of brain cellular membrane [11]. Works of Lorie- a Russian researcher- is an additional evidence for importance of movement, language and development. Many researchers have found that brain is a flexible structure which can be reshaped by stimulation though movements [12]. Behaviorist theorists believe movements can manifest how much an individual is motivated for a certain activity and can serve as an evidence to recognize how much the treatment has been effective. Cognitive theorists including Piaget stress the importance of initial feeling-movement skills as building blocks of cognitive-perceptional evolution. They believe evolution starts from feeling-movement stage by which infant begins to understand the world around through senses. According to Piaget theory, infant 
gains knowledge of the world through movement either physical or movement. In this stage, physical movement constitutes the most important source of gaining information and insight [13]. Generally, theories and researches of child growth and development demonstrate that children spend a variety of periods from early birth up to age of maturity. The first stage that they spend is feeling-movement one which takes place when child is infant close to childhood. In this period, they use their movement and senses to gain insight into the world around them. Touching, gripping, taking, abandonment, maintaining balance, creeping, creeping and walking help them get evolved into cognitive stage. Although hearing sense and musical - touching play important role in cognitive stage, what which makes child start to learn in this stage is cognitive- movement growth. Both of the above stages constitute a platform and basis for achievement of child to cognition. Having rich cognitive-movement experiment can be so much helpful for child to have a better ability to learn. There other theorists such as Gesell who care about the importance of movement learning on evolution of brain [14]. Numerous studies on neurological aspect of movement demonstrate that movement and sport trigger brain cells to grow causing blood circulation get better and neural-chemical activities of brain be improved: activity and movement increases blood flow into cortex which is accompanied by a rise in norepinephrine and dopamine in brain and initial movement-feeling areas of the brain and brain forehead. Physical exercise triggers density of circulating Beta Endorphin to increase significantly [15]. Also, there are evidences that show change of cerebellum structure improves cognitive function. These changes encompass a rise of neurogenesis substances that is useful for cognitive function. Studies of human indicate that adult's persons who have physical activity or participate in aerobic exercises would experience positive changes in their cerebellum helping them control their attention better. Researches further show that regular sport - based therapies contribute significantly to psychological and physical health [16]. Movement skill in ADHD children is notably lower than normal children [17]. Hyperactivity as a movement deficit disorder which is due to inefficient movement arrangement in individual making such individuals start to walk late. In its combinational form, it brings about movement-cognitive problems taking good performance away from such children [14]. These children are unable to move regularly and they are generally characterized by being awkward and clumsy. Such a problem has been reported for one third of ADHD children no matter if they are boys or girls [18]. This problem arises from weakness of atria, deep and touching systems. Therefore, movement inabilities in such children asserts itself in a variety of forms including lack of ability to maintain body balance or finding directions or lack of time/place/spatial conscious lack of ability to organize ordinary works and lack of delicate movement skills [14]. Play and sport open up a new window to conduct and education sciences. Slow and rhythmic movements and occasionally speedy movements can improve spatial image in mind and self-control ability as well as having body consciousness and relaxation. It can further enhance cognitivemovement abilities, physical balance and impulse control [18]. Such effect of sport and exercise was studied in a variety of research projects. Khalil's research (2002) showed that sport and playing with toys can improve child's self-balance, agility helping eye-hand coordinate and cognitive-movement abilities enhance [19]. Bakhsh poor et al (2013) confirmed effectiveness of collective play therapy on self-balance in standing position in ADHD children [14]. Researchers launched a study project titled 'impact of a Yoga practice period on practical functions in ADHD children'. He showed 12 sessions of Yoga practices exerts meaningful impact on practical functions (response inhibition, warned state, impulse control and position change). So, it seems that Yoga can be helpful in treatment of practical functions abnormalities in ADHD children [19]. Focused on relationship between regular bodily exercises with practical bodily functions in ADHD boys. It creates a remarkable potential to forecast four main practical bodily functions. The most notable effect had been observed in London Tower planning. In sum, findings of the research indicated that more physically actions, better memory and quicker processing data by 
memory and mind [14]. Researchers confirmed in their studies the effectiveness of sport and movement therapy in enhancement of practical functions of brain, memory and attention in ADHD children. Hence, these are evidences that persuade us sport and movement therapy are effective and helpful in treatment of ADHD children. Now we turn to our own hypothesis: making a treatment therapy plan in the form of Taekwondo and testing its effectiveness in easement of ADHD symptoms in boy [19]. It must be noted that this research has been designed and arranged on the basis of movement therapy in Taekwondo.

\section{Methodology}

This research is practical in terms of objective. It is a half-pilot study with test and control groups under a pre and posttest design for both groups. Statistical population and manner of sampling: statistical population is formed by all little boys suffering from ADHD in Tehran in 2019. Samples are 32 boys of 6 to 12 years of age who were ensured to have been diagnosed to be suffering from ADHD by psychiatric clinics. Samples were divided into two groups of test and control (each group 16 members). Test group was prescribed 12 sessions of 90 minutes movement therapy in the form of Taekwondo, and no intervention was assigned to control group. Pre and post-test instrument for each group was Conner's teaching questionnaire. Data, having been gathered, were analyzed in both descriptive and deductive scales. In descriptive analysis, average and standard deviations were focused; while in deductive single- variable covariance analysis was used through SPSS - version 22, to match and find the difference of groups in pre and posttest.

\section{Research Instrument}

Conner's teaching questionnaire questionnaires worked well in evaluation of symptoms of ADHD children. These questioners are used in the world for ADHD children. A main advantage of these questionnaires is their common usage in clinical diagnosis and having satisfactory validity and reliability in different cultural contexts. They contain 38 questions seeking to help teachers recognize if their students are suffering from ADHD or not [20].

\section{1. Validity and Reliability}

This questionnaire was considered by Conner et al in Canada in 1998. Range of alpha coefficients for seven subscale is 0.75 to 0.95 for boys and 0.76 to 0.94 for girls and reliability was ensured by retesting which found to be ranging from 0.47 (attention deficit) to 0.86 (oppositional disorder). The questionnaire was tested in Iran by Shahim et al. its validity was tested through retesting for the whole scale which was found to be 0.76 and for subscales 0.68 . Crohbash alpha coefficient for the total questionnaire was 0.86 and for subscales ranging from 0.74 for hyperactivity to 0.89 attention deficit and daydreaming [21].

\subsection{Scoring}

The questionnaire contains 38 four-item questions: $0=$ never, $1=$ very little, $2=$ average, $3=$ high, covering three aspects: 1 - child's conduct in classroom (questions 1-21), 2- participation in collective activities (22-29), 3- power sources (30-38). For evaluation purpose, the score 1.5 or higher means the child suffers from ADHD. On the other hand, since the questionnaire contains 38 questions, the total score ranges from 0 to 114. A score higher than 57 proves the disorder and as much as the score is higher the child is to that extent suffering from disorder, and vice -versa [22].

\subsection{Findings}

For the purpose of analysis, data were divided into descriptive and deductive categories. The first section of analysis deals with statistical indices and details as well as standard deviations in both groups of control and test before and after test. Second part deals with research hypothesis and parametric test were used. 


\section{4. Part 1: Descriptive Analysis}

Table 1. Descriptive indices for control group in before and after test $(\mathrm{n} 1=\mathrm{n} 2=16)$.

\begin{tabular}{cccccccc}
\hline \multicolumn{4}{c}{ Min. Max. average standard deviation } & & Variable & Indices \\
\cline { 1 - 6 } 5.818 & 76.88 & 69 & 88 & 16 & Pre-test & Attention deficit \\
\cline { 1 - 5 } & 76.19 & 68 & 86 & 16 & Post - test & and hyper activity \\
\hline
\end{tabular}

Data of Table 1 shows average and standard deviation for ADHD in pre and post tests for control group. As can be observed, difference of score is meager.

Table 2. Descriptive indices for test group in before and after test (n1=n2=16)

\begin{tabular}{|c|c|c|c|c|c|c|}
\hline \multicolumn{4}{|c|}{ Min. Max. average standard deviation } & & \multirow{2}{*}{$\begin{array}{l}\text { Variable } \\
\text { Pre-test }\end{array}$} & \multirow{2}{*}{$\begin{array}{c}\text { Indices } \\
\text { Attention deficit }\end{array}$} \\
\hline 4.856 & 75.88 & 69 & 89 & 16 & & \\
\hline 4.161 & 47.13 & 41 & 56 & 16 & Post - test & and hyper activity \\
\hline
\end{tabular}

Data of Table 2 shows average and standard deviation for ADHD in pre and post tests for test group. As can be observed, difference of score for boys in pre and posttest seems notable.

\section{5. Second Part}

In this part single-variable covariance analysis was used for analyzing deductive data. Author's hypothesis is that movement therapy decreases clinical symptoms of ADHD in boys participating in this research project.

\section{6. Deductive Data}

Before analyzing, assumptions, variable distribution normality, regression line slope and variances were checked and result of Levin related to variances homology of both groups in different stages of test were applied. These results are provided in Table 3.

\section{7. Variance consistency}

Table 3. Variance consistency (Levin test)

\begin{tabular}{ccccc}
\hline Meaningfulness & Df2 & Df1 & F & \\
\hline 0.099 & 30 & 1 & 2.906 & ADHD \\
\hline
\end{tabular}

Table 4. Summery of single-variable covariance analysis results

\begin{tabular}{ccccccc}
\hline $\begin{array}{c}\text { Effectiveness } \\
\text { coefficient }\end{array}$ & Meaningfulness & F coefficient & $\begin{array}{c}\text { Average } \\
\text { squares }\end{array}$ & Freedom & $\begin{array}{c}\text { Total } \\
\text { squares }\end{array}$ & $\begin{array}{c}\text { Variable source } \\
\text { of change }\end{array}$ \\
\hline 0.091 & 0.106 & 2.796 & 31.429 & 1 & 31.429 & ADHD \\
\hline 0.257 & 0.004 & 9.674 & 108.750 & 1 & 108.750 & Effect of therapy \\
\hline & & & 11.242 & 28 & 313.765 & Error \\
\hline & & & 32 & 129221 & Total \\
\hline
\end{tabular}

Above table shows a meaningful relationship between effectiveness of movement therapy on easement of clinical symptoms of boys suffering from ADHD in $\mathrm{P}<0.05$, 
$\mathrm{F}=9.674$. So, it can be concluded that movement therapy is effective on easement of clinical symptoms of boys suffering from ADHD in $\mathrm{P}<0.01, \mathrm{~F}=9.647$ ).

\section{Discussion and Conclusion}

This research seeks innovation in ddesign of a Movement Therapy in the form of Taekwondo and its Effectiveness on Easement of Clinical Symptoms in boys suffering from Deficit Attention and Hyper Activity Disorder [ADHD]. This research sought to test the hypothesis that 'movement therapy on easement of clinical symptoms of boys suffering from $\mathrm{ADHD}^{\prime}$. Our findings confirm the hypothesis. In this regard, can be noted in which a Yoga practice period was prescribed to ADHD children to check its effects on their practical functions. They found that a period of 12 week of Yoga practices had meaningful effect on practical function of such children. Therefore, it seems that Yoga be an effective way to improve practical functions disorders in ADHD children, which is compatible with our finding in this research. A study titled 'effect of aerobic practice and collective play therapy on ADHD children. In the study, 26 ADHD (four girls and twentytwo boys) were studied who were all suffering from ADHD. Three experimental groups (collective play therapy and aerobic) and a control group were created for the purpose of study: experimental groups were prescribed a period of 8 weeks, each week 3 sessions, of 45-60 long practices. Findings showed that in collective play therapy and aerobic group there is a meaningful relation in the effect of such prescription and dynamic balancing; while no such a relation was observed in relation to static balancing. It was concluded at the end that collective play therapy had stronger effect on ADHD children. But it was further recognized that aerobic was effective on static balancing as well. So, using aerobic practices in line with play therapy can work well in improvement of balance in ADHD children. These findings are compatible with research ours. In another research conducted relationship between regular bodily movements with practical functions was studied in ADHD boys. It was found that extent of movements can enable the occasion to forecast child's performance in four practical functions: the most remarkable effect of this activity was observed in London Tower planning. In sum, studies reveal that as much as much as physical movement is done memory and speed of processing is stronger. This finding is compatible with ours as well. A study focusing effect of delicate on improvement of attention in kindergarten children. They prescribed activities such as painting, coloring, writing and other such delicate activities. They found that members of experimental groups have better performance in terms of their cognitive score and attention score [17]. Approximately half of ADHD children suffer from weakness for which atria- cerebellum are involved. Imaging the brain of children confirms it. Since cerebellum and are involved in movement control and practical functions, a disturbance in such systems can be cited as the main reason for cognitive-movement defects in ADHD children [23].In relation to effectiveness of movement therapy on practical functions, physiologists and neurologists views are notable, because they believe movement stimulates neural paths and initial movement efforts is an integral part of brain's cellular membrane [12]. Furthermore, the importance of relationship between movement learning and language and growth development is evident in Loria comments who believes brain is a flexible structure which can be changed through stimulating by movement activities [15]. In addition to all these evidences, theorists of child growth including behavior lists, psycho-analysts and cognitivists who stress on the role of movement in growth serve another evidence [13].

\section{Limitations}

Movement therapy intervention needs a long time requiring a longitudinal research and failure to follow up the effectiveness of the therapy are min limitations of this research. 


\section{Recommendations}

Researchers are recommended to focus on ADHD girls in their future studies on movement therapy and ADHD children.

\section{References}

[1] Nelson, R, W, Israel, A.C. (2013). Behavior Disorder of childhood Cfitts Edition. New Jersey: Prentice Hall

[2] Goldstein. S. \& Goldstein, M, (1998). Managing attention deficit hyperactivity disorder in children: A guide for practitioners? New York: Wiley.

[3] Haljyn, Richard P. and Vitsborn, Susan Cross (2003), psychopathology, translation, John M. (2012), Tehran, Ravan publication.

[4] Alizadeh H. (2016). Attention deficit hyperactivity disorder (characteristics, assessment and treatment). Tehran, Iran: Roshd Press; [In Persian].

[5] Borjali and Mohammadi (2012), The relationship between the consumption of methylphenidate in children with attention deficit disorder and anxiety -More active. the Journal of Clinical Psychology and Personality: 6, pp. 34-44.

[6] Khalili, Z. (2014) Relationship between the effectiveness of cognitive behavioral therapy and behavioral therapy to reduce clinical symptoms in children with $\mathrm{AD}$ - hyperactivity, master's thesis, Islamic Azad University.

[7] Flaherty AW, Rost NS. Kaplan and Sadock's. (2011). Synopsis of psychiatry: Behavioral sciences/clinical psychiatry.10 ${ }^{\text {th }}$ ed. Philadelphia, PA: Lippincott Williams \& Wilkins.

[8] Ibrahimi, M., M. Varnoosfaderani, Abbas, Pvrmhmdrzay Rehabilitation, M and wise person, F. (2013), The effectiveness of sensory integration activities - move on AD symptoms - hyperactivity. Journal of Rehabilitation, No. 9, p. 220231.

[9] Saif Ali Akbar (2010), Behavior changes and health behavior theories and methods, Tehran: Doran Publication.

[10] 10- Azimi, R., (2015), Planning a movement therapy program to evaluate its effectiveness in reducing visual perception errors move children with specific learning disorder, clinical psychology master's thesis, Islamic Azad University.

[11] Berthoz F (2000). Diagonis \& Management \& Learning Disabilities. A College- Hill Publication: Boston

[12] Fredericks, A. Krog\&Kokot, S. (2006). Impact \& different definitions \& Learning disabilities. Journal \& Psychoeducation and Assessment, 3: 341-52.

[13] Gallahue\&Ozmun. (2006) Analysis \& reading difficulty n.k, psychological corporation, 2 intz, miles, reading process. Brown co. N.t.

[14] Sadati, Firozabadi, (2013), EffectsMotor therapy program on clinical symptoms, executive function and well-being of ADHA Student snd Its comparison with neurofeed back therapy, psychology doctoral thesis, Tehran University.

[15] Kleamber, K.A and Forness, S.r, (2004). Hyperactivity and dieftreatment. Journal \& Learning disabilities, 26: 324-330.

[16] Khalahi H, Emad M, (2010). Effect of selected movement program on perceptual-motor function of 4-6 years old children. Movement Science and Sport; 1: 30-42. [In Persian].

[17] Verret C, Gardiner P, Beliveau L, (2010). Fitness level and gross motor performance of children with attention-deficit hyperactivity disorder. Adapt Phys Activ Q; 27(4): 337-51.

[18] Bakhshipour, Elham, guidance, Nader Sourtchi, Hussein, Eskandari and Zahra Izadi Najaf Abadi, S. (2013), The effect of aerobic exercise and balance group play therapy on children with attention deficit disorder and hyperactivity. magazine Research in Rehabilitation Sciences, No. 2, pp. 161-170.

[19] Biek, Nezakatolhusseini, almond and Abedi (2014), The effects of yoga programs on executive function in children with attention deficit and hyperactivity disorders. Journal of Research in Rehabilitation Sciences - 1393 - Volume 10 - Number 4 - Page: 528 538.

[20] Ratey, F, H \& Hagerman, J L. 2008). Educating Exceptional children, USA, Houghton, Mifflin Company.

[21] Shahim, Sima, Yousefi, Farideh and Shhayyan, A. (2007), Attributes specific standardized psychometric rating scale Kanrzteachers. Journal of Education and Psychology martyr Chamran University, No. 1, pp. 1-26

[22] Conners C. (1997). Conners' rating scales :revised technical manual. North Tonawanda (NY). Multi-Health Systems, online. Avalable from URL: http :www.mhs.com Assessed 2008 Mar 3

[23] Cheung PP, Siu AM, (2009). A comparison of patterns of sensory processing in children with and without developmental disabilities. Res Dev Disabil; 30(6): 1468-80. 